ISSN: 2302-8556

E-Jurnal Akuntansi Universitas Udayana

Vol.26.2.Februari (2019): 1412-1435

DOI: https://doi.org/10.24843/EJA.2019.v26.i02.p21

\title{
Pengaruh Love Of Money, Machiavellian, dan Equity Sensitivity Terhadap Persepsi Etika Penggelapan Pajak (Tax Evasion)
}

\author{
Ni Putu Sri Murtining Asih ${ }^{1}$ \\ Kadek Trisna Dwiyanti ${ }^{2}$ \\ ${ }^{1,2}$ Fakultas Ekonomi dan Bisnis Universitas Pendidikan Nasional (Undiknas), \\ Bali, Indonesia \\ e-mail: tuning.murtining@yahoo.com
}

\begin{abstract}
ABSTRAK
Penelitian ini bertujuan untuk mengetahui pengaruh love of money, machiavellian, dan equity sensitivity terhadap persepsi etika wajib pajak atas penggelapan pajak di Kantor Pelayanan Pajak Pratama Denpasar Timur. Populasi dalam penelitian ini adalah seluruh wajib pajak orang pribadi yang terdaftar di Kantor Pelayanan Pajak Pratama Denpasar Timur. Jumlah sampel yang digunakan dalam penelitian ini adalah sebanyak 100 responden dari 76.543 populasi wajib pajak orang pribadi yang masih efektif di Kantor Pelayanan Pajak Pratama Denpasar Timur pada tahun 2017. Besarnya sampel dihitung berdasarkan rumus slovin dengan teknik penentuan sampel metode accidental sampling. Pengumpulan data dalam penelitian ini dilakukan dengan metode kuesioner. Teknik analisis data yang digunakan adalah analisis regresi linier berganda. Hasil penelitian menunjukkan bahwa love of money dan Machiavellian berpengaruh negatif terhadap persepsi etika penggelapan pajak, sedangkan equity sensitivity tidak berpengaruh terhadap persepsi etika penggelapan pajak.

Kata kunci: Love of money, machiavellian, equity sensitivity, persepsi etis, penggelapan pajak (tax evasion).
\end{abstract}

\begin{abstract}
This study aims to know the influence of love of money, machiavellian, and equity sensitivity toward individual taxpayer's ethical perception of tax evasion in east-denpasar tax office. Population in this study are whole registered individual-taxpayer in east-denpasar tax office.The number of samples used are 100 of 76543 active individual-tax payer that registered until 2017. The amount of samples were counted based on slovin with accidental sampling method. Data collection are conducted by questionnaire method in this study. Data analysis technique used is Multiple Linear Regression Analysis. The result of this study indicates that love of money and machiavellian make negative effect on taxpayer's ethical perception of tax evasion, but equity sensitivity does not influence on taxpayer's ethical perception of tax evasion.

Keywords: Love of money, machiavellian, equity sensitivity, ethical perception, tax evasion.
\end{abstract}

\section{PENDAHULUAN}

Kontribusi pajak dalam beberapa tahun terakhir ini semakin meningkat dan diperhitungkan sebagai sumber pendapatan negara untuk mewujudkan programprogram pembangunan nasional. 
Ni Putu Sri Murtining Asih dan Kadek Trisna Dwiyanti. Pegaruh...

Tabel 1.

Realisasi Penerimaan Pajak Tahun 2015-2017

\begin{tabular}{clll}
\hline Tahun & $\begin{array}{l}\text { Target } \\
\text { Penerimaan Pajak } \\
\text { (Triliun Rupiah) }\end{array}$ & $\begin{array}{l}\text { Realisasi } \\
\text { Penerimaan Pajak } \\
\text { (Triliun Rupiah) }\end{array}$ & $\begin{array}{l}\text { \% } \\
\text { Penerimaan Pajak }\end{array}$ \\
\hline 2015 & 1.489 & 1.240 & $83,3 \%$ \\
2016 & 1.539 & 1.284 & $83,4 \%$ \\
2017 & 1.498 & 1.343 & $89,6 \%$ \\
\hline Sumber: www.kemenkeu.go.id, 2018 & &
\end{tabular}

Berdasarkan Tabel 1.1 dapat dilihat penerimaan negara dari sektor pajak dalam tahun terakhir tidak mencapai target yang telah ditetapkan. Hal tersebut mengindikasi bahwa masih terdapat wajib pajak yang tidak patuh membayar pajak sehingga penerimaan pajak yang diperoleh belum optimal. Ketidakpatuhan wajib pajak yang dimaksud ialah tindakan-tindakan wajib pajak yang melanggar UU Perpajakan seperti penghindaran dan penggelapan pajak (Handayani, 2008).

Salah satu alasan bagi para wajib pajak melakukan tindakan penggelapan pajak dapat dipengaruhi oleh kecintaannya terhadap uang yang tinggi karena menurut (Sloan, 2002) kecintaan terhadap uang atau "the love of money" adalah keinginan manusia terhadap uang atau keserakahannya.Selain itu, faktor lain yang dianggap dapat mempengaruhi wajib pajak melakukan tindakan yang tidak etis yaitu sifat machiavellian, dimana McLaughin(1970) mengemukakan bahwa individu dengan sifat machiavellian tinggi cenderung lebih berbohong, kurang bermoral, dan lebih manipulatif. Selain kedua faktor tersebut, equity sensitivity juga dianggap dapat mempengaruhi perilaku wajib pajak dalam bertindak etis dan tidak etis, dimana equity sensitivity merupakan suatu persepsi seseorang terhadap keadilan dengan membandingkan antara inputs dan outcomes yang diperoleh dari orang lain (Ustadi \& Utami, 2005) 
Etika erat kaitannya dengan moralilitas dan menghindari tindakantindakan yang buruk. Tindakan etis wajib dipengaruhi oleh lingkungan dan karateristik individual. Love of money, machiavellian, dan equity sensitivity ialah salah satu karakter seseorang yang dapat mendorong seseorang untuk melakukan tindakan tidak etis.

Yesi Mulia Basri (2015)telah melakukan penelitian mengenai pengaruh love of money terhadap persepsi etis penggelapan pajak. Penelitian ini merupakan pengembangan dari penelitian tersebut dengan menambahkan beberapa variabelvariabel lain seperti machiavellian dan equity sensitivity yang dianggap dapat mempengaruhi perilaku etis seseorang. Oleh karena itu, peneliti termotivasi untuk meneliti pengaruh love of money, machiavellian, dan equity sensitivity terhadap persepsi etika wajib pajak atas penggelapan pajak.

Adapun rumusan masalah dalam penelitian iniyaitusebagai berikut: 1) apakah Love of Money berpengaruh terhadap persepsi etika penggelapan pajak?, 2) apakah Machiavellian berpengaruh terhadap persepsi etika penggelapan pajak?, dan 3) apakah Equity Sensitivityberpengaruhterhadap persepsi etika penggelapan pajak?.

Penelitian ini diharapkan dapat memberikan manfaat baik dari segi teoritis maupun praktis. Adapun manfaat teoritisnya, penelitian ini diharapkan dapat mampu menambah dan mengembangkan wawasan, informasi, serta pemikiran dan ilmu pengetahuan yang khususnya berkaitan dengan persepsi etika terkait penggelapan pajak. Selain itu, penelitian ini diharapkan dapat menjadi masukan bagi para generasi muda sebagai calon wajib pajak, dengan lebih memperhatikan perkembangan moral ataupun perkembangan etis mereka agar 
Ni Putu Sri Murtining Asih dan Kadek Trisna Dwiyanti. Pegaruh...

dapat membentuk karakter yang jujur terkait hal pajak dan dapat memberikan kontribusi dan menjadi acuan terhadap ilmu akuntansi yang berkaitan dengan persepsi etis.Selanjutnya, untuk manfaat praktispenelitian ini mampu meningkatkan tingkat kepatuhan wajib pajak orang pribadi dan mengantisipasi adanya tindakan-tindakan penggelapan pajak (tax evasion) yang mungkin dilakukan oleh wajib pajak di KPP Pratama Denpasar Timur berdasarkan sikap dan karakteristik individu yang dinilai dari kecintaannya terhadap uang (love of money), ketergantungannya dalam melakukan manipulasi untuk mencapai tujuan (machiavellian), dan persepsi atas keadilan yang diperoleh dari orang lain (equity sensitivity) yang akan mempengaruhinya dalam berperilaku etis.

Theory of Planned Behavior (TPB) yang merupakan teori yang dikembangkan oleh (Ajzen, 1985) dengan menambahkan satu faktor lagi yakni perceived behavioral control. TPB adalah teori yang digunakan untuk mengukur niat perilaku seseorang sebagai perilaku prediktor yang menggambarkan hubungan antara keyakinan (beliefs), sikap (attitudes), perilaku (behavior) dan perceived behavior control. TPB relevan untuk menjelaskan penelitian ini, karena salah satu faktornya yaitu attitude toward the behavior memiliki keterkaitan dengan love of money, machiavellian dan equity sensitivity yang mana seseorang cenderung memikirkan konsekuensi positif dan negatif yang akan diperoleh dari melakukan suatu perilaku dalam hal ini terkait (tax evasion).Individu yang memiliki sikap love of money, machiavellian, dan equity sensitivity cenderung menghubungkan antara perilaku dengan berbagai konsekuensinya baik manfaat atau kerugian yang mungkin akan diperolehnya apabila berperilaku tersebut (outcome evaluation) (Ajzen, 2005). 
Penelitian sebelumnya pernah dilakukan oleh Elias (2010) yang menguji hubungan antara perilaku cinta uang (love of money) dengan persepsi etis dan menghasilkan pengaruh yang negatif. Hasil penelitian ini didukung oleh Tang dan Chiu (2003) yang mengemukakan bahwa etika uang seseorang memiliki dampak yang negatif pada etika penggelapan pajak. Berpengaruh negatif menunjukan bahwa "Tingginyamoney ethicyang dimiliki seseorang mengindikasi besarnya kemungkinan seseorang untuk berperilaku tidak etis”. Kochan (2002) juga mengemukakan bahwa kecintaan uang yang berlebihan akan menyebabkan terjadinya kecurangan berupa memaksimalkan keuntungan pemegang saham.

Sedangkan penelitian yang dilakukan oleh Luna dan Arocas (2004) memperoleh hasil yang berbeda dengan menyimpulkan bahwa love of money terbukti tidak memotivasi professor di Amerika Serikat dan Spanyol untuk melakukan tindakan yang tidak etis.

Berdasarkan hasil penelitian sebelumnya, maka hipotesis yang dirumuskan adalah sebagai berikut:

$\mathrm{H}_{1}$ : Love of money berpengaruh negatif terhadap persepsi etika penggelapan pajak pada wajib pajak orang pribadi (WP OP)

Yuliana (2012) menyatakan bahwa pengaruh perilaku machiavellian terhadap persepsi etis yakni semakin tinggi tingkat machiavellian yang dimiliki seseorang maka semakin besar kemungkinan seseorang tersebut untuk melakukan tax evasion. Hasil penelitian ini sejalan dengan penelitian Tri Suci Ramadhani (2015) yang mengemukakan bahwa sifat machiavellian berpengaruh negatif terhadap pengambilan keputusan etis terkait dalam hal ini yaitu penghindaran pajak. Pengaruh negatif yang dimaksud yakni tingginya sifat machiavellian yang 
Ni Putu Sri Murtining Asih dan Kadek Trisna Dwiyanti. Pegaruh...

dimiliki seseorang, mengindikasi keputusan yang akan diambilnya semakin tidak etis. Berdasarkan hasil penelitian sebelumnya, maka dapat dirumuskan sebagai berikut :

$\mathrm{H}_{2}$ : Machiavellian berpengaruh negatif terhadap persepsi etika penggelapan pajak pada wajib pajak orang pribadi (WP OP)

Equity sensitivity merupakan suatu persepsi seseorang terhadap keadilan dengan membandingkan antara inputs dan outcomes yang diperoleh dari orang lain (Ustadi \& Utami, 2005). Mueller dan Clarke (1998) menunjukan bahwa equity sensitivity berpengaruh terhadap perilaku etis seseorang. Hasil penelitian ini juga didukung oleh Eni Widiastuti (2015) dalam penelitiannya mengemukakan bahwa equity sensitivity berpengaruh terhadap perilaku etis seseorang akuntan. Hal serupa juga dinyatakan oleh Elex Sarmigi (2018)bahwa terdapat pengaruh positif dan signifikan equity sensitivity terhadap perilaku etis mahasiswa akuntansi, namun penelitian-penelitian tersebut berbanding terbalik dengan Nursiah (2010) dan Susanti (2014) yang mengemukakan bahwa equity sensitivity tidak memiliki pengaruh yang signifikan terhadap perilaku etis seorang akuntan.

Berdasarkan hasil dari penelitian sebelumnya, maka dapat dirumuskan sebagai berikut :

$\mathrm{H}_{3}=$ Equity Sensitivity berpengaruh signifikan dan positif terhadap persepsi etika penggelapan pajak pada wajib pajak orang pribadi (WP OP)

\section{METODE PENELITIAN}

Metode dalam penelitian ini menggunakan metode pendekatan kuantitatif yang bersifat asosiatif. Penelitian ini dilakukan di Kantor Pelayanan Pajak (KPP) Pratama Denpasar Timur yang beralamat di Jalan Letda Tantular No.4 Renon, 
Denpasar.Obyek penelitian ini adalah wajib pajak orang pribadi di KPP Pratama Denpasar Timur.

Penelitian ini menggunakan dua variabel yaitu variabel independen (bebas) danvariabel dependen (terikat). Variabel independen (X) yang digunakan dalam penelitian ini yaitulove of money, machiavellian, dan equity sensitivity. Variabellove of money diukur menggunakan money ethic scale (MES) berdasarkan enam faktor yang diidentifikasi, meliputi good, evil, achievement, respect, budget, dan freedom(Furnham \& Argyle, 2008). Faktor-faktor tersebut kemudian menjadi 11 pernyataan yang diadopsi dari penelitian Ferawati Harun(2016). Skala pengukuran yang digunakan adalah skala Likert modifikasi 5 poin dengan rincian sebagai berikut: a) Sangat Setuju (SS) diberi skor 5; b) Setuju (S) diberi skor 4; c) Netral (N) diberi skor 3; d)Tidak Setuju (TS) diberi skor 2; dan e) Sangat Tidak Setuju (STS) diberi skor 1.

Variabel machiavellian diukur menggunakan skala mach IVdengan 20 pernyataan yang mengadopsi indikator Christie dan Geis (1970). Skala pengukuran yang digunakan adalah skala Likert modifikasi 5 poin dengan rincian sebagai berikut: a) Sangat Setuju (SS) diberi skor 5; b) Setuju (S) diberi skor 4; c) Netral (N) diberi skor 3; d) Tidak Setuju (TS) diberi skor 2; dan e) Sangat Tidak Setuju (STS) diberi skor 1. Variabel equity sensitivity diukur menggunakan Equity Preference Questionnaire (EPQ) berdasarkan 12 pernyataan yang mengadopsi indikator penelitian Eni Widiastuti (2015) dalam tiga kategori yaitu benevolent, sensitives, dan entitelds. Skala pengukuran yang digunakan adalah skala Likert modifikasi 5 poin dengan rincian sebagai berikut: a) Sangat Setuju (SS) diberi skor 5; b) Setuju (S) diberi skor 4; c) Netral (N) diberi 
Ni Putu Sri Murtining Asih dan Kadek Trisna Dwiyanti. Pegaruh...

skor 3; d) Tidak Setuju (TS) diberi skor 2; dan e) Sangat Tidak Setuju (STS) diberi skor 1 .

Variabel dependen (Y) yang digunakan yaitu persepsi etika penggelapan pajak. Etika penggelapan pajak diukur berdasarkan 4 pernyataan yang mengadopsi indikator penelitian Trie Julianti Dewi (2016) yaitu: a) Penerapan tarif pajak dan pentingnya kerjasama yang baik antara fiskus dan Wajib Pajak, b) Lemahnya pelaksanaan hukum pajak dan terdapat peluang Wajib Pajak dalam melakukan penggelapan pajak, c) Integritasatas mentalitas aparaturper pajakan atau fiskus dan pejabat pemerintah yang buruk serta pendiskriminasian terhadap perlakuan pajak, d) Konsekuensi melakukan penggelapan pajak. Skala pengukuran yang digunakan adalah skala Likert modifikasi 5 poin dengan rincian sebagai berikut: a) Sangat Setuju (SS) diberi skor 5; b) Setuju (S) diberi skor 4; c) Netral (N) diberi skor 3; d) Tidak Setuju (TS) diberi skor 2; dan e) Sangat Tidak Setuju (STS) diberi skor 1.

Populasi adalah generalisasi yang terdiri atas subjek atau objek yang mempunyai kualitas dan karakteristik tertentu yang ditetapkan oleh peneliti untuk dipelajari dan kemudian ditarik kesimpulannya (Sugiyono, 2014). Populasi dalam penelitian ini adalah 76.543 Wajib Pajak Orang Pribadi efektif yang terdaftar di KPP Pratama Denpasar Timur berdasarkan data yang diperoleh dari KPP Pratama Denpasar Timur. Guna efisiensi waktu dan biaya maka peneliti melakukan pengambilan sampel.

Sampel adalah bagian dari jumlah dan karakteristik yang dimiliki oleh populasi tersebut (Sugiyono, 2014). Sampel pada penelitian akan dipilih sedemikian rupa sehingga dapat mewakili sifat-sifat populasi (Sugiyono, 2014). 
Jumlah sampel ditentukan dengan rumus Slovin. Berdasarkan perhitungan dengan rumus slovin, banyaknya sampel yang diambil pada penelitian ini adalah 100 Wajib Pajak Orang Pribadi.Metode penentuan sampel pada penelitian ini adalah accidental sampling. Accidental sampling dilakukan secara subjektif oleh peneliti ditinjau dari sudut kemudahan tempat pengambilan sampel dan jumlah sampel yang akan diambil (Rahyuda, 2014). Pengumpulan datadilakukan dengan metode survei menggunakan media angket (kuesioner).

Jenis data yang digunakan dalam penelitian ini adalah data kuantitatif. Data kuantitatif yaitu data dalam bentuk angka yang dapat dinyatakan dan dapat diukur dengan satuan hitung (Sugiyono, 2014). Data kuantitatif dalam penelitian ini berupa jumlah wajib pajak orang pribadi efektif pada KPP Pratama Denpasar Timur dan hasil kuesioner yang merupakan jawaban dari responden. Sumber data berdasarkan sumber yang digunakan dalam penelitian ini adalah data primer dan data sekunder. Data primer adalah data yang diperoleh secara langsung dari sumber aslinya dan tidak melalui media perantara (Sugiyono, 2014). Sedangkan, data sekunder adalah sumber data penelitian yang tidak langsung memberikan data kepada pengumpul data, misalnya melalui orang atau dokumen (Sugiyono, 2014). Data primer dalam penelitian ini adalah jawaban responden dan kuesioner yang disebar oleh peneliti. Data sekunder yang dimaksud yaitu data-data yang diperoleh dari KPP Pratama Denpasar Timur, www.kemenkeu.go.id, dan Kantor Wilayah Direktorat Jenderal Pajak Bali.

Teknik analisis data dalam penelitian ini diawali dengans uji instrumenpenelitians terdiri daris uji validitasdan uji reliabilitas. Uji validitas dilakukan dengan melakukan korelasi bivarite antara masing-masing skor 
Ni Putu Sri Murtining Asih dan Kadek Trisna Dwiyanti. Pegaruh...

indikator dengan total skor konstruk dengan menggunakan correlation coeficients pearson(Ghozali, 2016). Validnya suatu kuesioner dapat dilihat dari nilai $\mathrm{r}$ hitung yang lebih besar dari 0,30 (Ghozali, 2016). Kuesioner dikatakan reliabel apabila nilai cronbach alpha yang diperoleh lebih besar dari 0,70(Ghozali, 2016).

Uji asumsi klasik dalam penelitianini terdiri dari uji normalitas, uji multikolonieritas dan uji heteroskedastisitas.Uji normalitas dapat dilakukan dengan menggunakan One Sample Kolmogorov-Smirnov Test, dengan taraf signifikan 0,05 atau 5\%. Jika signifikan yang dihasilkan >0,05 maka distribusi datanya dikatakan normal. Sebaliknya, jika signifikan yang dihasilkan $<0,05$ maka data tidak terdistribusi secara normal (Ghozali, 2016b). Uji multikolonieritas dapat dilakukan dengan melihat nilai tolerence atau Varience Inflation Factor (VIF). Tolerence mengukur variabel bebas yang terpilih dan tidak dijelaskan oleh variabel bebas lainnya. Jika nilai tolerence lebih dari $10 \%$ atau VIF kurang dari 10, maka model dikatakan bebas dari gejala multikolonieritas (Ghozali, 2016;105). Uji heteroskedastisitas yang digunakan dalam penelitian menggunakan uji glejser. Dalam pengujian Glejser menggunakan koefisien signifikansi probabilitas pada tingkat ketelitian 5\%, jika lebih besar dari sama dengan 5\% maka dapat disimpulkan model regresi tidak mengandung adanya heteroskedastisitas (Ghozali, 2016).

Teknik analisis data yang digunakan dalam penelitian ini adalah analisis regresi linier berganda. Analisis linier berganda adalah pengujian yang dilakukan untuk mengetahui ada tidaknya pengaruh love of money $\left(\mathrm{X}_{1}\right)$, machiavellian $\left(\mathrm{X}_{2}\right)$, dan equity sensitivity $\left(\mathrm{X}_{3}\right)$ pada persepsi etika penggelapan pajak (Y). 
Model Regresi Linier Berganda ditunjukan dalam persamaan sebagai berikut:

$Y=\alpha+\beta_{1} X_{1}+\beta_{2} X_{2}+\beta_{3} X_{3}+\varepsilon$

Keterangan :

Y= Persepsi Etika Penggelapan Pajak

$\alpha=$ Nilai Konstanta

$\beta_{1}=$ Koefisien regresi dari love of money $\left(\mathrm{X}_{1}\right)$

$\beta_{2}=$ Koefisien regresi dari Machiavellian $\left(\mathrm{X}_{2}\right)$

$\beta_{3}=$ Koefisien regresi dari equity sensitivity $\left(\mathrm{X}_{3}\right)$

$\mathrm{X}_{1}=$ Love of Money

$\mathrm{X}_{2}=$ Machiavellian

$\mathrm{X}_{3}=$ Equity Sensitivity

$\varepsilon=$ Kesalahan pengganggu (standard error)

\section{HASILDAN PEMBAHASAN}

Pengumpulan data dalam penelitian ini menggunakan instrumen kuesioner yang dibagikan kepada wajib pajak orang pribadi efektif yang terdaftar pada KPP Pratama Denpasar Timur. Penyebaran dilakukan di wilayah KPP Pratama Denpasar Timur sebanyak 100 kuesioner dengan pengisian lengkap sehingga 100 kuesioner tersebut dapat digunakan. Tabel 2 menyajikan formasi penyebaran kuesioner.

Tabel 2.

Tingkat Pengembalian Kuesioner

\begin{tabular}{lc}
\hline \multicolumn{1}{c}{ Keterangan } & Jumlah \\
\hline Jumlah kuesioner yang disebar & 100 \\
Kuesioner yang dikembalikan & 100 \\
Tingkat pengembalian (response rate) & $100 \%$ \\
Kuesioner yang dikembalikan/kuesioner yang disebar x 100\% & \\
Tingkat pengembalian yang digunakan (usable response rate) & $100 \%$ \\
Kuesioner yang digunakan/kuesioner yang disebar x 100\% &
\end{tabular}

Sumber: Data diolah, 2018 
Ni Putu Sri Murtining Asih dan Kadek Trisna Dwiyanti. Pegaruh...

Karakteristik responden dibagi menjadi beberapa kelompok menurut jenis kelamin digunakan untuk mengetahui proporsi wajib pajak orang pribadi lakilaki dan perempuan, usia digunakan untuk mengetahui rentang umur WPOP, serta tingkat pendidikan yang digunakan untuk mengetahui tingkat pengetahuan dan intelektualitas yang dimiliki oleh WPOP dalam mematuhi ketentuan perpajakan. Karakteristik responden penelitian disajikan pada Tabel 4.

Tabel 3.

Karakteristik Responden Penelitian

\begin{tabular}{|c|c|c|}
\hline Keterangan & Jumlah & Persentase \\
\hline \multicolumn{3}{|c|}{ Jenis Kelamin } \\
\hline a. Laki-laki & 44 & $44 \%$ \\
\hline $\begin{array}{l}\text { b. } \\
\text { Perempuan }\end{array}$ & 56 & $56 \%$ \\
\hline Total & 100 & $100 \%$ \\
\hline \multicolumn{3}{|c|}{ Usia } \\
\hline a. $\quad 20-30$ & 20 & $20 \%$ \\
\hline b. $\quad 31-40$ & 38 & $38 \%$ \\
\hline c. $\quad 41-50$ & 32 & $32 \%$ \\
\hline d. $>50$ & 10 & $10 \%$ \\
\hline Total & 100 & $100 \%$ \\
\hline
\end{tabular}

Tingkat Pendidikan:
a. SMA
25
$25 \%$
b. Diploma
16
$16 \%$ 

a. $\mathrm{S} 1$
49
$49 \%$
b. $\mathrm{S} 2$
10
$10 \%$
c. Lainnya
0
$0 \%$
Total
100
$100 \%$

Sumber: Data diolah, 2018

Berdasarkan Tabel 3 bahwa mayoritas responden penelitian ini adalah perempuan yaitu sebanyak $56 \%$ dan sisanya adalah laki laki. Dari segi usia mayoritas berumur 31 sampai 40 tahun yaitu sebesar 38\%.Responden dengan tingkat pendidikan S1 berada di posisi tertinggi yaitu sebanyak 49 orang atau sebesar $49 \%$.

Uji Validitas adalah suatu ukuran yang menunjukkan tingkat-tingkat kevalidan atau kesahihan suatu instrumen (Arikunto, 2010:211). Tabel 4 menyajikan hasil uji validitas.

Tabel 4.

Hasil Uji Validitas

\begin{tabular}{|c|c|c|c|c|}
\hline \multicolumn{5}{|c|}{ ji } \\
\hline \multirow{3}{*}{ No } & \multirow{3}{*}{ Variabel } & Kode & Koefisien & \multirow{3}{*}{ Keterangan } \\
\hline & & & & \\
\hline & & Instrumen & Korelasi & \\
\hline \multirow{11}{*}{1} & \multirow{11}{*}{$\begin{array}{c}\text { Love of Money } \\
\text { (X1) }\end{array}$} & $\mathrm{X} 1.1$ & 0,647 & Valid \\
\hline & & $\mathrm{X} 1.2$ & 0,323 & Valid \\
\hline & & $\mathrm{X} 1.3$ & 0,546 & Valid \\
\hline & & $\mathrm{X} 1.4$ & 0,636 & Valid \\
\hline & & $X 1.5$ & 0,851 & Valid \\
\hline & & X1.6 & 0,731 & Valid \\
\hline & & X1.7 & 0,828 & Valid \\
\hline & & $\mathrm{X} 1.8$ & 0,338 & Valid \\
\hline & & X1.9 & 0,349 & Valid \\
\hline & & $\mathrm{X} 1.10$ & 0,749 & Valid \\
\hline & & $\mathrm{X} 1.11$ & 0,768 & Valid \\
\hline 2 & Machiavellian & $\mathrm{X} 2.1$ & 0,549 & Valid \\
\hline
\end{tabular}


Ni Putu Sri Murtining Asih dan Kadek Trisna Dwiyanti. Pegaruh...

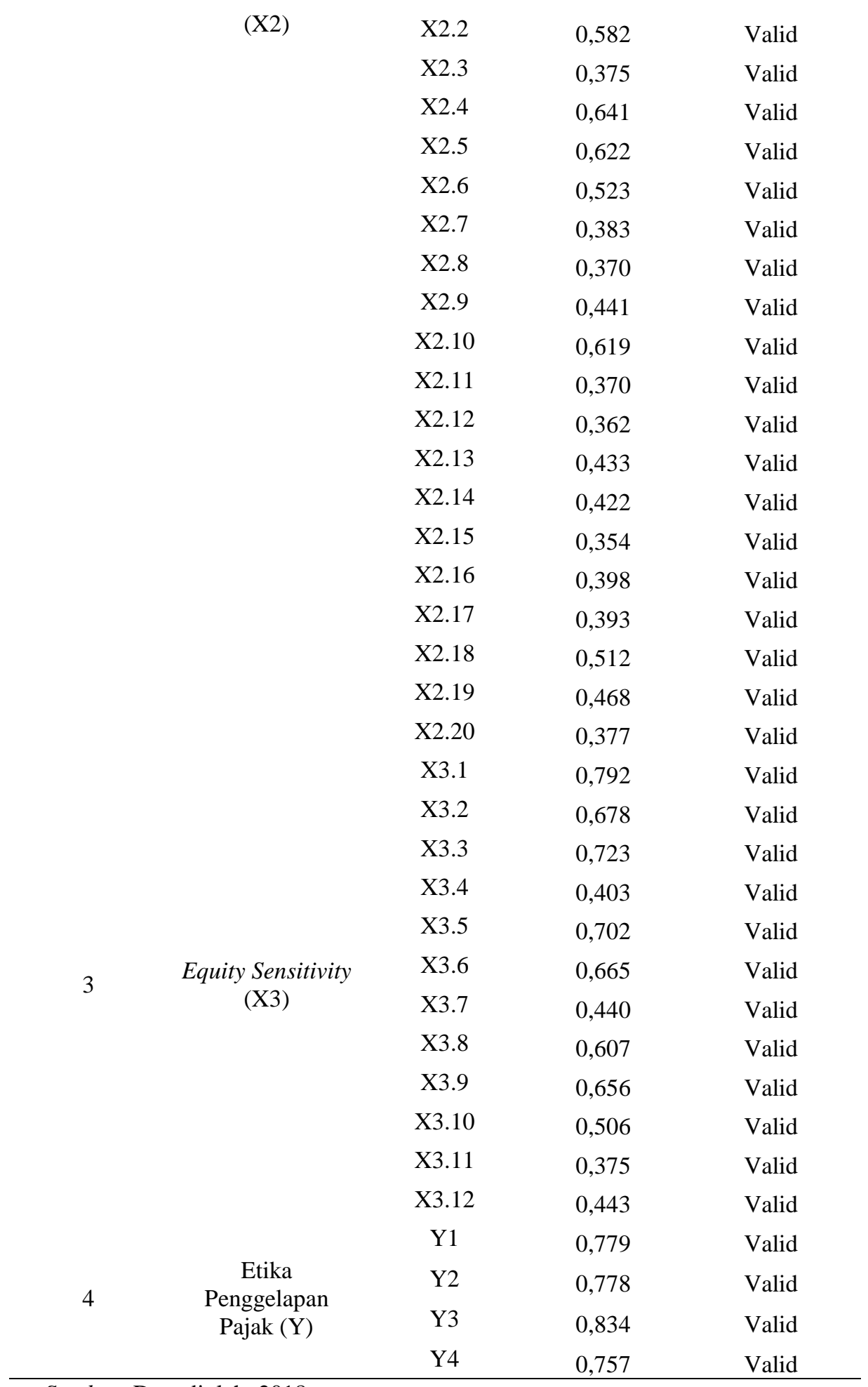

Sumber: Data diolah, 2018 
Berdasarkan Tabel 4menunjukkan bahwa instrumen penelitian yang terdiri dari $\mathrm{X}_{1}, \mathrm{X}_{2}, \mathrm{X}_{3}$, dan $\mathrm{Y}$ memiliki nilai koefisien korelasi yang lebih besar dari 0,30 . Jadi, seluruh indikator pernyataan tersebut telah memenuhi syarat validitas data.

Uji reliabilitas digunakan untuk mengukur konsistensi hasil pengukuran dari kuesioner dalam penggunaan yang berulang.Jika nilai koefisien Cronbach Alpha $(\alpha)>0,7$ maka pertanyaan/pernyataan dinyatakan andal.Tabel 6 menyajikan hasil uji reliabilitas.

Tabel 5.

Hasil Uji Reliabilitas

\begin{tabular}{clcl}
\hline No & \multicolumn{1}{c}{ Variabel } & Cronbach's Alpha & Keterangan \\
\hline 1 & Love of Money (X1) & 0,847 & Reliabel \\
2 & Machiavellian (X2) & 0,790 & Reliabel \\
3 & Equity Sensitivity (X3) & 0,832 & Reliabel \\
4 & Etika Penggelapan Pajak (Y) & 0,789 & Reliabel \\
\hline
\end{tabular}

Sumber: Data diolah, 2018

Berdasarkan Tabel 5 menunjukkan bahwa nilai Cronbach Alpha masingmasing variabel lebih besar dari 0,70. Sehingga, dapat disimpulkan bahwa pernyataan dalam kuesioner penelitian ini reliabel dan dapat digunakan.

Uji normalitas digunakan untuk menguji variabel residualnya memiliki distribusi normal atau tidak. Uji normalitas dalam penelitian ini menggunakan uji statistik non-parametrik One Sample Kolmogorov-Smirnov Test. Residual berdistribusi normal apabila Asymp.Sig. lebih besar dari $\alpha=0,05$ (Ghozali, 2016b). 
Ni Putu Sri Murtining Asih dan Kadek Trisna Dwiyanti. Pegaruh...

Tabel 6.

Hasil Uji Normalitas

\begin{tabular}{lr}
\hline \multicolumn{2}{c}{ Unstandardized Residual } \\
\hline $\mathrm{N}$ & 100 \\
$\begin{array}{l}\text { Asymp.Sig. } \\
\text { (2-tailed) }\end{array}$ & 0,077 \\
Sumber: Data diolah, 2018 &
\end{tabular}

Berdasarkan Tabel 6 menunjukkan bahwa unstandardized residual memiliki nilai Asymp.Sig. (2-tailed) sebesar 0,077 yang lebih besar dari taraf signifikansi 0,05. Hal ini berarti seluruh data berdistribusi normal.

Pengujian multikolonieritas bertujuan untuk menguji apakah dalam model regresi ditemukan adanya korelasi antar variabel bebas. Apabila nilai VIF kurang dari 10 atau nilai tolerance lebih besar dari 0,1 (10\%), maka dapat dikatakan bahwa tidak ada multikolenieritas. Hasil uji multikolonieritas disajikan pada Tabel 7.

Tabel 7. Hasil Uji Multikolonieritas

\begin{tabular}{lcc}
\hline \multicolumn{1}{c}{ Variabel } & Tolerance & VIF \\
\hline Love of Money (X1) & 0,799 & 1,252 \\
Machiavellian (X2) & 0,698 & 1,432 \\
Equity Sensitivity (X3) & 0,843 & 1,187 \\
\hline Sumber: Data diolah, 2018 & &
\end{tabular}

Berdasarkan Tabel 7 dapat dilihat hasil uji multikolonieritas menunjukkan bahwa nilai tolerance masing-masing variabel lebih besar dari 0,1 dan nilai VIF lebih kecil dari 10. Jadi dapat disimpulkan bahwa dalam regresi tersebut tidak terjadi multikolonieritas.

Pengujian heteroskedastisitas dalam penelitian ini menggunakan uji Glejser. Tingkat probabilitas signifikansi masing-masing variabel bebas jika lebih 
besar dari 0,05 maka dapat disimpulkan tidak terdapat heteroskedastisitas. Hasil uji heteroskedastisitas disajikan pada Tabel 8.

Tabel 8.

Hasil Uji Heteroskedastisitas

\begin{tabular}{ccc}
\hline Variabel & Sig. & Keterangan \\
\hline Love of Money (X1) & 0,940 & Bebas Heteroskedastisitas \\
Machiavellian $(\mathrm{X} 2)$ & 0,773 & Bebas Heteroskedastisitas \\
Equity Sensitivity (X3) & 0,912 & Bebas Heteroskedastisitas
\end{tabular}

Sumber: Data diolah, 2018

Berdasarkan Tabel 8 menunjukkan bahwa nilai signifikansi masingmasing variabel lebih besar 0,05. Jadi, dapat disimpulkan bahwa model regresi dalam penelitian ini bebas dari gejala heteroskedastisitas.

Tabel 9.

\section{Hasil Uji Koefisien Determinasi}

Model Summary

\begin{tabular}{rrrrr}
\hline Model & R & R Square & $\begin{array}{l}\text { Adjusted } \\
\text { R Square }\end{array}$ & $\begin{array}{l}\text { Std. Error of } \\
\text { the Estimate }\end{array}$ \\
\hline 1 & $.485^{\mathrm{a}}$ & .235 & .179 & 315.849 \\
\hline
\end{tabular}

a. Predictors: (Constant), EQ, MONEY, MACHV

Sumber: Data diolah, 2018

Koefisien determinasi digunakan untuk mengukur sejauh mana kemampuan variabel independen dalam menerangkan variasi variabel dependen.Berdasarkan Tabel 9 Angka adjusted $R$ square sebesar 0,179 menunjukkan bahwa hanya 17,9\% variabel persepsi etika penggelapan pajak yang bisa dijelaskan oleh variabel love of money, machiavellian, dan equity sensitivity. Dan sisanya $82,1 \%$ dijelaskan faktor lain.

Tabel 10. 


\section{Hasil Uji Analisis Regresi Linier Berganda}

Coefficients $^{\mathrm{a}}$

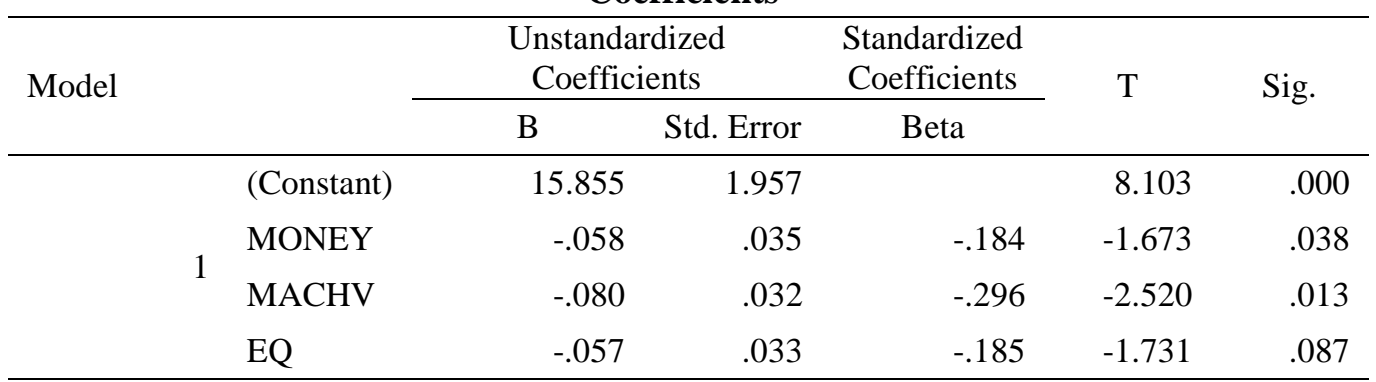

a. Dependent Variable: EVASION

Sumber:Data diolah, 2018

Berdasarkan Tabel 10 dapat disusun persamaan regresi sebagai berikut:

$Y=15.855+(-0,058) X_{1}+(-0,080) X_{2}+(-0,057) X_{3}+\varepsilon$

Berdasarkan persamaan diatas, dapat dijelaskan hal-hal sebagai berikut:

Nilai konstanta sebesar 15.855 menunjukan bahwa bila nilai love of money $\left(\mathrm{X}_{1}\right)$, machiavellian $\left(\mathrm{X}_{2}\right)$, dan equity sensitivity $\left(\mathrm{X}_{3}\right)$ sama dengan nol, maka nilai persepsi etika penggelapan pajak (Y) meningkat sebesar 15.855 satuan. Nilai koefisien $\beta_{1}=-0,058$ berarti mengindikasi bahwa love of money $\left(\mathrm{X}_{1}\right)$ berpengaruh negatif terhadap persepsi etika penggelapan pajak (Y). Hal ini menunjukkan bahwa dengan penambahan satu satuan love of money maka akan terjadi penurunan sebesar 0,058 . Nilai koefisien $\beta_{2}=-0,080$ berarti mengindikasi bahwa machiavellian $\left(\mathrm{X}_{2}\right)$ berpengaruh negatif terhadap persepsi etika penggelapan pajak (Y).

Hal ini menunjukkan bahwa dengan penambahan satu satuan machiavellian maka akan terjadi penurunan sebesar 0,080. Nilai k oefisien $\beta_{3}=-0,057$ berarti menunjukkan bila equity sensitivity $\left(X_{3}\right)$ bertambah 1 satuan, maka nilai dari persepsi etika penggelapan pajak (Y) akan mengalami penurunan sebesar 0,057 satuan dengan asumsi variabel bebas lainnya konstan. 
Uji kelayakan model (uji F) dilakukan untuk menguji variabel independen yang digunakan bersifat layak digunakan atau tidak sebagai penjelas atau prediktor. Dari Tabel 10 menunjukkan nilai signifikansi $\mathrm{F}$ adalah sebesar 0,000 yang lebih kecil dari 0,05. Hal ini menunjukkan love of money, machiavellian, dan equity sensitivity berpengaruh secara bersama-sama terhadap persepsi etika penggelapan pajak. Hal ini berarti model regresi dalam penelitian ini layak digunakan $(f i t)$.

Uji hipotesis (uji t) dilakukan untuk mengetahui apakah ada pengaruh yang signifikan antara variabel bebas terhadap variabel terikat. Level of significant ( $\alpha$ ) yang digunakan adalah $5 \% . \mathrm{H}_{\mathrm{i}}$ diterima jika $p$-value $<\alpha=0,05$. Berdasarkan Tabel 10 menunjukkan t hitung love of money adalah sebesar -1,673 dengan signifikan $\mathrm{t}$ bernilai 0,038 . Hal ini menunjukan bahwa love of money berpengaruh negatif terhadap persepsi etika penggelapan pajak, sehingga hipotesis pertama dalam penelitian ini diterima.

Berdasarkan Tabel 10 menunjukkan t hitung machiavellianadalah sebesar 2,520 dengan signifikan $\mathrm{t}$ bernilai 0,013yang lebih kecil dari $\alpha=0,05$. Hal ini menunjukan bahwa hipotesis kedua dalam penelitian ini diterima yaitu,machiavellian berpengaruh negatif terhadap persepsi etika penggelapan pajak.

Berdasarkan Tabel 10 menunjukkan t hitung equity sensitivity adalah sebesar -1,731 dengan signifikan $\mathrm{t}$ bernilai 0,087, dimana nilai sig. $\mathrm{t}$ lebih besar dari $\alpha=0,05$. Hal ini menunjukan bahwa hipotesis ketiga dalam penelitian ini ditolak yaitu, equity sensitivity tidak berpengaruh terhadap persepsi etika penggelapan pajak. 
Ni Putu Sri Murtining Asih dan Kadek Trisna Dwiyanti. Pegaruh...

\section{SIMPULAN}

Penelitian ini betujuan untuk mengetahui pengaruh love of money, machiavellian, dan equity sensitivity terhadap persepsi etika penggelapan pajak di KPP Pratama Denpasar Timur. Berdasarkan hasil penelitian yang dilaksanakan di KPP Pratama Denpasar Timur tentang persepsi etika wajib pajak orang pribadi terhadap penggelapan pajak (tax evasion), maka dapat disimpulkan beberapa hal yaitu: 1) Love of money berpengaruh negatif terhadap persepsi etika penggelapan pajak pada wajib pajak orang pribadi. Semakin tinggi sifat love of money yang dimiliki oleh wajib pajak, maka persepsi wajib pajak atas etika penggelapan pajak juga makin tinggi, dimana wajib pajak akan cenderung melakukan penggelapan pajak dan perilaku tersebut dianggap etis oleh wajib pajak karena kecintaannya terhadap uang, 2) Machiavellian berpengaruh negatif terhadap persepsi etika penggelapan pajak pada wajib pajak orang pribadi. Semakin tinggi sifat machiavellian yang dimiliki oleh wajib pajak maka persepsi wajib pajak atas etika penggelapan pajak juga makin tinggi, dimana wajib pajak akan cenderung melakukan penggelapan pajak yang dianggap etis oleh wajib pajak karena kepribadiannya yang cenderung mengabaikan moralitas demi keuntungan dirinya sendiri, 3) Equity sensitivity dinyatakan tidak dapat mempengaruhi perilaku etis wajib pajak dalam hal pemenuhan kewajiban perpajakannya dimana wajib pajak tidak terpicu untuk melakukan tindakan kecurangan yaitu penggelapan pajak atas keadilan yang diterima karena bersifat relatif. 
Berdasarkan hasil penelitian serta simpulan, adapun saran yang dapat diberikan untuk penelitian ini adalah sebagai berikut: 1) Bagi Kantor Pelayanan Pajak Pratama Denpasar Timur, dalam upaya meminimalisir adanya tindakan penggelapan pajak Kantor Pelayanan Pajak Pratama Denpasar Timur yang merupakan instansi vertikal di bawah Kantor Wilayah Direktorat Jenderal Pajak agar lebih aktif memberikan sosialisasi berupa pandangan dan motivasi kepada wajib pajak agar wajib pajak sadar bahwa etika penggelapan pajak merupakan suatu tindakan yang sangat tidak etis. Selain itu, dalam upaya menghindari adanya tindakan penggelapan pajak, Kantor Pelayanan Pajak Pratama Denpasar Timur harus meningkatkan sistem perpajakan dengan selalu meng-updatesystem menjadi lebih canggih lagi yang mampu mendeteksi apabila terdapat kecurangan pajak (warning system), sehingga dapat mengantisipasi tindakan wajib pajak yang diduga akan melakukan penggelapan pajak; 2) Bagi Wajib Pajak, disarankan agar lebih aktif mengikuti sosialisasi dan pelatihan yang diadakan oleh Direktorat Jenderal Pajak dan juga wajib pajak disarankan secara rutin mengakses website Direktorat Jenderal Pajak guna meningkatkan pengetahuan terkait perpajakan; 3)Bagi Peneliti Selanjutnya yang tertarik meneliti di bidang yang sama dapat menggunakan variabel-variabel yang tidak digunakan dalam penelitian ini, hal ini dilakukan karena koefesien dalam koefesien determinasi dalam penelitian ini masih dapat ditingkatkan dengan adanya penambahan variabel bebas dan juga memperbanyak jumlah responden dan juga memperluas ruang lingkup penelitian, hal ini agar memperoleh jawaban dan hasil penelitian yang lebih baik. 
Ni Putu Sri Murtining Asih dan Kadek Trisna Dwiyanti. Pegaruh...

\section{REFERENSI}

Ajzen, I. (1985). From Intentions To Actions: A Theory Pf Planned Behavior. In J. Kuhl And J. Beckman (Eds.), Action Control: From Cognition To Behavior, 11-39.

Ajzen, I. (2005). Attitudes, Personality And Behavior, (2nd Edition),. UK: Open University Press-Mcgraw Hill Education.

Alabede, J. O., Ariffin, Z. Z., \&Idris, K. M. (2011). Individual Taxpayers ' Attitude And Compliance Behaviour In Nigeria: The Moderating Role Of Financial Condition And Risk Preference. Journal Of Accounting And Taxation, 3(September), 91-104.

Arikunto. (2010). Prosedur Penelitian Suatu Pendekatan Praktik. Jakarta: Rineka Cipta.

Aryobimo, P. T., \&Cahyonowati, N. (2012). Pengaruh Persepsi Wajib Pajak Tentang Kualitas Pelayanan Fiskus Terhadap Kepatuhan Wajib Pajak Dengan Kondisi Keuangan Wajib Pajak Dan Preferensi Risiko Sebagai Variabel Moderating (Studi Empiris Terhadap Wajib Pajak Orang Pribadi Di Kota Semarang). Diponegoro Journal Of Accounting, 1(2), 1-12.

Basri, Y. M. (2015). Pengaruh Gender, Religiusitas Dan Sikap Love Of Money Pada Persepsi Etika Penggelapan Pajak Mahasiswa Akuntansi. Jurnal Ilmiah Akuntansi Dan Bisnis, 10(1), 45-54.

Christie, R., \&Geis, F. I. (1970). Scale Construction. Studies In Machiavellianism, New York. Academic Press.

Dewi, N. K. T. J. (2016). Pengaruh Keadilan Pajak, Sistem Perpajakan, Diskriminasi, Pengetahuan Wajib Pajak, Dan Intensitas Pemerikasaan Pajak Pada Persepsi Wajib Pajak Orang Pribadi Mengenai Etika Atas Penggelapanpajak (Tax Evasion). Udayana, E-Jurnal Akuntansi Universitas.

Elias, R. Z. (2010). The Relationship Between Accounting Students' Love Of Money And Their Ethical Perception. Managerial Auditing Journal, 25(3). 
Feld, L. P., \&Frey, B. S. (2006). Tax Compliance As The Result Of A Psychological Tax Contract: The Role Of Incentives And Responsive Regulation. Law And Policy, 29(1), 102-120. Https://Doi.Org/10.1111/J.1467-9930.2007.00248.X.

Frey, B. S., \&Torgler, B. (2007). Tax Morale And Conditional Cooperation. Journal Of Comparative Economics. Journal Of Comparative Economics, 35(1), 136-159.

Furnham, A., \&Argyle, M. (2008). The Psychology Of Money. London: Routledge.

Ghozali, I. (2016a). Aplikasi Analisis Multivariate Dengan Program IBM Dan SPSS 21. In Aplikasi Analisis Multivariate Dengan Pogram Iibm SPSS 21 (P. 113). Semarang: Badan Penerbit Universitas Diponegoro. Https://Doi.Org/10.2307/1579941

Ghozali, I. (2016b). Statistik Non-Parametrik: Teori Dan Aplikasi Dengan Program SPSS. Universitas Diponegoro. Semarang.

Handayani, D. (2008). Analisis Hubungan Tingkat Kepatuhan Wajib Pajak Orang Pribadi Dengan Penerimaan Pajak Pada Kantor Pelayanan Pajak Pekanbaru Senapelan. Jurnal Akuntansi Keuangan Dan Bisnis.

Harun, F. (2016). Pengaruh Sifat Machiavellian Dan Love Of Money Terhadap Perilaku Etis Auditor (Studi Kasus Pada BPK RI Perwakilan Provinsi Sulawesi Selatan). Jurnal Islam Negeri Alauddin Makassar.

Kirchler E, Hoelzl E, W. I. (2007). Enforced Versus Voluntary Tax Compliance: The Slippery Slope Framework. Journal Of Economy Psychology, 29(2), 210-225.

Kochan, T. A. (2002). Addressing The Crisis In Confidence In Corporations: Root Causes, Victims, And Strategies For Reform. Academy Of Management Executive.

Luna R., Arocas, \&Tang, T. L. . (2004). The Love Of Money, Statisfaction, And The Protestant Work Ethic: Money Profile Among University Professors In The USA And Spain. Journal Of Bussines Ethic, 50(329-54).

Mclaughin, G. (1970). Incidental Learning And Machiavellianism. Journal of Social Psychology, 82, 109-115.

Mueller, S. L., \&Clarke, L. D. (1998). Political-Economic Context And Sensitivity To Equity: Differences Between The United States And The Transition Economics Of Central And Eastern Europe. Academy Of Management Journal, 41(3), 319-329. 
Ni Putu Sri Murtining Asih dan Kadek Trisna Dwiyanti. Pegaruh...

Nursiah. (2010). Analisis Faktor-Faktor Individual Dalam Etika Profesi Yang Mempengaruhi Perilaku Etis Auditor Pada Kantor Akuntan Publik (Kap) Di Pekanbaru Diajukan. Jurnal Ekonomi Dan Ilmu Sosial Universitas Islam Negeri Sultan Syarif Kasim Riau.

Rahyuda. (2014). Metodologi Penelitian. Denpasar: Udayana Press.

Ramadhani, Tri Suci. (2015). Pengaruh Sifat Machiavellian, Locus Of Control, Dan Equity Sensitivity Terhadap Penghindaran Pajak Dengan Keputusan Etis Sebagai Variabel Intervening. Jom. Fekon, 2.

Sarmigi, E. (2018). Analisis Komparasi Perilaku Etis Mahasiswa Akuntansi Stie Sakti Alam Kerinci Dengan Stie Sumatera Barat Dan Faktor-Faktor Yang Mempengaruhinya. Jurnal Akuntansi \&Ekonomi ( JAE ), 3(2541-0180), 1.

Sloan, A. (2002). The Jury's In : Greed Isn't Good (News Week).

Sugiyono. (2014). Penelitian Pendidikan Pendekatan Kuantitatif, Kualitatif, Dan $R \& D$. Bandung: Alfabeta.

Susanti, B. (2014). Pengaruh Locus Of Control, Equity Sensitivity, Ethical Sensitivity Dan Gender Terhadap Perilaku Etis Akuntan. Jurnal Universitas Negeri Padang.

Tang, T., \&Chiu, R. (2003). Income, Money Ethic, Pay Satisfaction, Commitment, And Unethical Behaviour: Is The Love Of Money The Root Of Evil For Hongkong Employees? Journal Of Bussiness Ethic, 46, 13-30.

Ustadi, N. ., \&Utami, R. D. (2005). “Analisis Perbedaan Faktor-Faktor Individual Terhadap Persepsi Perilaku Etis Mahasiswa. Jurnal Akuntansi \&Auditing, 1(02), 162-180.

Widiastuti, E. (2015). Pengaruh Orientasi Etis, Equity Sensitivity, Dan Budaya Jawa Terhadap Perilaku Etis Auditor Pada Kantor Akuntan Publik Di Yogyakarta. Jurnal Ekonomi Universitas Negeri Yogyakarta, 3.

Yuliana. (2012). Analisis Pengaruh Persepsi Pentingnya Etika Dan Tanggung Jawab Sosial, Sifat Machiavellian, Dan Keputusan Etis Terhadap Niat Berpartisipasi Dalam Penghindaran Pajak (Studi Empiris Pada Konsultan Pajak Di Semarang). Undergraduate Thesis Universitas Diponegoro. 